\title{
Immunogenicity of Therapeutic Proteins: The Use of Animal Models
}

\author{
Vera Brinks • Wim Jiskoot $•$ Huub Schellekens
}

Received: 23 March 2011 / Accepted: 27 June 2011 / Published online: 9 July 2011

(C) The Author(s) 2011. This article is published with open access at Springerlink.com

\begin{abstract}
Immunogenicity of therapeutic proteins lowers patient well-being and drastically increases therapeutic costs. Preventing immunogenicity is an important issue to consider when developing novel therapeutic proteins and applying them in the clinic. Animal models are increasingly used to study immunogenicity of therapeutic proteins. They are employed as predictive tools to assess different aspects of immunogenicity during drug development and have become vital in studying the mechanisms underlying immunogenicity of therapeutic proteins. However, the use of animal models needs critical evaluation. Because of species differences, predictive value of such models is limited, and mechanistic studies can be restricted. This review addresses the suitability of animal models for immunogenicity prediction and summarizes the insights in immunogenicity that they have given so far.
\end{abstract}

KEY WORDS animal models · immunogenicity · therapeutic proteins

V. Brinks $(\bowtie) \cdot H$. Schellekens

Department of Pharmaceutics

Utrecht Institute for Pharmaceutical Sciences, Utrecht University

Universiteitsweg 99

3584 CG Utrecht, The Netherlands

e-mail:v.brinks@uu.nl

\section{W. Jiskoot}

Division of Drug Delivery Technology

Leiden/Amsterdam Center for Drug Research (LACDR)

Leiden University

P.O. Box 9502, 2300 RA Leiden, The Netherlands

H. Schellekens

Department of Innovation and Environmental Sciences

Utrecht University, Faculty of Geosciences

P.O. box 801 I5, 3508 TC Utrecht, The Netherlands

\author{
ABBREVIATIONS \\ BLAST basic local alignment search tool \\ $C D$ cluster of differentiation \\ HLA human leucocyte antigen \\ MHC major histocompatibility complex \\ PEG polyethylene glycol \\ PLGA poly(lactide-co-glycolide) \\ tPA tissue plasminogen activator
}

\section{INTRODUCTION}

Therapeutic proteins have revolutionized the treatment of diseases such as diabetes, multiple sclerosis and rheumatoid arthritis. An advantage of these drugs is that they do not possess intrinsic toxicity due to harmful metabolites; they are broken down to amino acids (1). Furthermore, therapeutic proteins are highly versatile. By recombinant DNA techniques, monoclonal antibodies can be designed to bind to various endogenous molecules in order to affect their function. As a result, therapeutic proteins now make up around $30 \%$ of the marketed drugs, and many more are under development.

Immunogenicity is a major disadvantage of these protein drugs. Almost all therapeutic proteins induce an antibody response (2). While such an antibody response does not necessarily cause severe side effects, clinical implications can occur. Antibody formation may lead to a loss of efficacy, neutralization of the endogenous counterpart or general immune system effects (i.e., serum sickness like disease, infusion reactions, anaphylaxis and anaphylactoid reactions) (3-6). To prevent antibody-induced side effects and thereby warrant better patient well-being and lower therapeutic costs, it is important to treat patients with 
therapeutic proteins that have no or minimal immunogenicity $(7,8)$. Animal models may be useful in developing such low immunogenic drugs.

First, animal models are used as predictive tools during drug development. The European Medicine Agency (EMA) states that although predictive value of animal models is considered low, they should be considered for selected immunogenicity studies (9). In fact, the predictive value of animal models depends on both the type of animal model and what needs to be predicted.

Second, animal models can help to elucidate the mechanisms underlying antibody responses against therapeutic proteins (10). Such knowledge is vital in developing novel therapeutic protein products with low immunogenicity.

The next sections focus on the suitability of various animal models to predict immunogenicity and describe their use in elucidating the mechanisms underlying immunogenicity.

\section{ANIMAL MODELS AS TOOL TO PREDICT IMMUNOGENICITY IN HUMANS}

Although animal models are commonly used to assess drugrelated toxicity, there is still a debate on their suitability for immunogenicity prediction during drug development. One of the reasons for this debate is the difficulty of validation. Although several studies using animal models in immunogenicity prediction are published (11-15), only a few have bridged the gap between animals and human patients $(16,17)$. Most of the current studies only give an indication on whether animals could be used to predict different aspects of immunogenicity.

Classically, non-transgenic mice, rats and non-human primates have been used. For proteins that are conserved across species, non-human primates might have some predictive value. Transgenic mouse models have been used in immunogenicity prediction of proteins that are less conserved between mice and humans $(13,18)$.

The predictive value of animal models depends on the similarity in processes underlying immunogenicity compared to those in human patients. Because these processes are still relatively unknown, we assume that animal models "closest" to humans in terms of genetic background are most predictive. According to this assumption, conventional animal models such as rats and mice would have the least predictive value, followed by transgenic animal models, and non-human primates would have the highest predictive value.

Another important issue in immunogenicity prediction is what needs to be predicted. Examples are the prediction of 1) neo-epitopes on modified proteins, 2) relative immunogenicity between products, 3) breaking of tolerance, 4) immunogenicity in patients, 5) incidence of immunogenicity in patients, and 6) clinical consequences of antibody development (for example cross-reactive neutralizing antibodies) (Table 1 for glossary). While some aspects might be "easy" to predict, such as relative immunogenicity between products, others, such as incidence of immunogenicity in patients, are not (Table 2). In fact, incidence of immunogenicity in patients is predominantly determined during the post-marketing stage. However, phase 3 studies might also give an estimate on the incidence of immunogenicity in patients when a product has relative high immunogenicity, sufficient patients are included, and an immunological response develops during the study duration. The next sections will discuss the predictive potential of animal models for different immunogenicity topics.

\section{Conventional Experimental Animals}

Most human therapeutic proteins are foreign proteins for conventional animals such as mice and rats. These animals will therefore develop a classical immune response against a foreign molecule when treated with these foreign proteins, while patients develop antibodies to these types of products by another mechanism, most likely by breaking of B-cell tolerance (10). Patients with Fabry disease, haemophilia and other innate deficiencies who lack tolerance to these products and may produce antibodies to alpha galactosidase, factor VIII and other proteins via the classical immune response are the exception (4).

Because the mechanisms underlying immunogenicity differ between conventional animal models and humans, the value of these models is limited. Most studies show that conventional animal models over-estimate immunogenicity in patients (19), making them unsuitable to predict (incidence of) immunogenicity in patients. Several researchers have proposed that conventional models might be able, for some proteins, to predict relative immunogenicity. Jaber and colleagues used BALB/c mice to screen and select a low immunogenic formulation of Rebif ${ }^{\circledR}$ (human interferon beta-IFN $\beta$ 1a). The formulation with lowest immunogenicity proved to be less immunogenic compared to the current IFN $\beta$ la product at that time in a Phase I clinical trial (20). Other researchers have also used BALB/c mice to assess relative immunogenicity of IFN $\beta$ products (21).

However, conventional animal models are less likely to predict clinical consequences of immunogenicity such as development of neutralizing antibodies and presence of neo-epitopes on modified proteins. This again is due to the different mechanisms underlying antibody response. Because the therapeutic protein is foreign, the immune response against it will involve T-helper cell recruitment, affinity maturation, and neutralizing antibody development (Table 1) (22). It is therefore expected that conventional animal models over-estimate neutralizing antibody devel- 
Table I Glossary

\begin{tabular}{|c|c|}
\hline Term & Explanation \\
\hline Antigenicity & $\begin{array}{l}\text { The ability of a compound (e.g., a therapeutic protein) to bind to components of the adaptive immune system } \\
\text { (e.g., antibodies). }\end{array}$ \\
\hline Immunogenicity & The capability of a compound (e.g., a protein) to induce an immune response (e.g. anti-drug antibodies). \\
\hline Epitope & $\begin{array}{l}\text { A specific part of a compound (e.g., a peptide sequence in a protein) that is recognized by a product of the } \\
\text { immune system (e.g., an antibody). }\end{array}$ \\
\hline Neo-epitope & $\begin{array}{l}\text { A novel epitope that is formed due to protein modification, such as amino-acid substitution, or chemical or } \\
\text { physical degradation. }\end{array}$ \\
\hline Non-neutralizing antibody & $\begin{array}{l}\text { An antibody that binds to the therapeutic protein but does not affect its intrinsic activity/receptor binding; } \\
\text { however, it may change its pharmacokinetics and thus affect therapeutic efficacy. Also referred to as } \\
\text { binding antibody. }\end{array}$ \\
\hline Neutralizing antibody & $\begin{array}{l}\text { An antibody that binds to the active site of the therapeutic protein and thereby inhibits its function. } \\
\text { As a result, efficacy will be diminished, and therapy failure can occur. }\end{array}$ \\
\hline Tolerance & $\begin{array}{l}\text { Immunological non-reactivity to a therapeutic protein, usually resulting from previous exposure to the endogenous } \\
\text { counterpart of that protein. }\end{array}$ \\
\hline
\end{tabular}

opment. Prediction of neo-epitopes will have similar problems. Because therapeutic proteins are foreign to the animals, multiple epitopes will be expressed. If protein modification would lead to a new epitope, expression of this epitope is likely overwhelmed by expression of the epitopes that are already present on the unmodified protein. An example is a mouse study performed by Katsutani and colleagues (23). The aim of the study was to detect newly exposed epitopes on an analogue of human tissue plasminogen activator (mt-PA6), compared to native sequence human tissue plasminogen activator (tPA). Their results suggest that the antibodies formed in the mt-PA6-treated mice are directed mainly against epitopes present in the native sequence human tPA that have not been altered in the analogue

In summary, there are some suggestions that conventional animal models could assess relative immunogenicity between products (also discussed later on). However, these models have no predictive value for assessing (occurrence of) immunogenicity in humans, neutralizing antibodies or neo-epitopes.

\section{Transgenic Immune Tolerant Animals}

To overcome a classical immune response against "foreign" therapeutic proteins in conventional animal models, immunetolerant transgenic mice that express the protein of interest have been developed. The mechanisms underlying antibody formation against the corresponding therapeutic protein are therefore expected to be similar to the mechanisms in humans.

One of the first immune-tolerant transgenic mouse models for immunogenicity studies was the human tPA mouse model developed by Stewart and colleagues in 1989 (24). This transgenic mouse model was used to evaluate the induction of neo-epitopes by amino acid substitution of human tPA. When challenged with a form of tPA in which a single amino acid was substituted, the transgenic mice produced antibodies recognizing human tPA. The authors therefore concluded that modifying therapeutic proteins could have immunological consequences in patients. Another transgenic mouse model developed to assess the induction of new epitopes by protein modification was the human insulin-expressing mouse model (25). This model

Table 2 Predictive Potential of Animal Models for Different Aspects of Immunogenicity

\begin{tabular}{|c|c|c|c|c|c|c|}
\hline \multirow[b]{2}{*}{ Animal model } & \multicolumn{6}{|c|}{ Predictive potential for } \\
\hline & Neo-epitopes & $\begin{array}{l}\text { Relative } \\
\text { immunogenicity }\end{array}$ & Breaking of tolerance & $\begin{array}{l}\text { Immunogenic } \\
\text { potential in } \\
\text { patients }\end{array}$ & $\begin{array}{l}\text { Incidence of } \\
\text { immunogenicity }\end{array}$ & $\begin{array}{l}\text { Clinical consequences } \\
\text { of antibody } \\
\text { development }\end{array}$ \\
\hline Conventional & No $(10)$ & Yes $(||)$ & No & No $(12)$ & No $(12)$ & Unlikely \\
\hline Transgenic & Yes $(13,14)$ & Yes (15) & Yes (16) & Unlikely & No (| 5) & $?$ \\
\hline $\begin{array}{l}\text { Non-human } \\
\text { primates }\end{array}$ & $\begin{array}{l}\text { In theory yes }(10) \text {, } \\
\text { but depends on } \\
\text { protein }\end{array}$ & Yes $(10,17)$ & $\begin{array}{l}\text { In theory yes, but } \\
\text { depends on protein } \\
(16,17)\end{array}$ & $\begin{array}{l}\text { Possibly } \\
\qquad(17,18)\end{array}$ & Unlikely & Possibly (19) \\
\hline
\end{tabular}


has been used to study immunogenicity of several human insulin analogues (12). The authors found that the incidence of antibodies against insulin correlated with an increase in the number of substitutions on the insulin molecule. They therefore state that transgenic mice could be used to characterize the relative immunogenicity of different protein analogues. These studies on tPA and insulin show that transgenic mouse models are capable of detecting neo-epitopes as a result of protein modification.

Transgenic mouse models have also been used to assess relative immunogenicity. One of these models is the human interferon beta transgenic mouse model $(13,26)$. Our research group has shown that the interferon beta product with highest immunogenicity in patients (Betaseron) also has highest immunogenicity in the mouse model (13). However, we observe almost no difference in immunogenicity between Avonex and Rebif, although their immunogenicity profile in patients differs. (27). Also, the incidence of immunogenicity in the mice does not correspond to the incidence in patients.

In another study, we looked at whether conjugation of a PEG group to the interferon beta protein would affect antibody response. PEGylation is a commonly used modification to improve the pharmacokinetic profile of a protein and is not primarily intended to decrease its immunogenicity. None of the PEGylated and non-PEGylated interferon-betatreated transgenic mice developed an antibody response (13). Apparently, conjugation of PEG to interferon beta does not affect immunogenicity for this protein. Lee and colleagues have used transgenic immune-tolerant mice to assess whether a formulation of human growth hormone $(\mathrm{GH})$ containing PLGA microspheres would break tolerance for GH (28). They showed that both the microsphere-free and microsphere-containing formations did not evoke an antibody response in the transgenic mice. The authors concluded that in the case of homologous proteins like GH, PLGAcontaining formulations do not induce a break of tolerance or act as adjuvant. Fradkin and colleagues have used a similar GH transgenic mouse model to study if an aggregatecontaining formulation would be able to induce an antibody response. They showed that none of the aggregatecontaining solutions was able to induce antibody formation (29). This contrasts a finding reported in the study by Lee, in which GH aggregates did appear to induce an antibody response in their transgenic mice (unpublished finding by $\mathrm{J}$. Cleland, E. Duenas and A. Jones). The type of aggregate and experimental setup would have contributed to this discrepancy.

Besides transgenic mouse models that express human proteins resembling therapeutic proteins, the use of HLA transgenic mice also in combination with the immune-tolerant models has been suggested to predict immunogenicity. HLA transgenic mice express human MHC and should in theory be able to present similar epitopes as patients. Combined transgenics expressing $\mathrm{MHC}$ and the human protein of interest might also be useful to answer the question whether the breaking of tolerance is restricted to certain HLA types.

In summary, transgenic animal models can be used to predict neo-epitopes, relative immunogenicity, and breaking of tolerance. However, they are likely less suitable to predict the incidence of immunogenicity or clinical effect of antibody formation. HLA transgenics may be an interesting additional tool to study whether the immunogenic response is HLA restricted.

\section{Non-Human Primates}

Because the proteins of humans and non-human primates show a high degree of homology, non-human primates should be tolerant for most human proteins. The mechanisms underlying their antibody response would therefore likely be similar to the human response.

The toxicology research group of Eli Lilly, including Zwickl and Wierda, has performed several experiments to study the translational value of rhesus monkeys in immunogenicity research $(11,14,15,17)$. In one study, rhesus monkeys were treated with recombinant methionyl-human growth hormone (hGH), pituitary-derived hGH or recombinant natural sequence hGH in order to assess relative immunogenicity between products. Only 4 out of 190 amino acids differ between the human and monkey protein (28). However, it has been suggested that rhesus monkeys are not tolerant for human GH (28). The authors found antibody responses in, respectively, $81 \%, 69 \%$ and $5-23 \%$ of the monkeys, which correlates with clinical observations in terms of relative immunogenicity (17). The authors therefore conclude that rhesus monkeys might be useful in predicting relative immunogenicity of some human proteins. In contrast, the absolute incidence of antibodypositive individuals, in the case of $\mathrm{GH}$, was not predicted.

In another study, the same research group compared immunogenicity of tissue plasminogen activator (tPA) and a plasminogen activator analogue (mt-PA6) in rhesus monkeys (15). Both native-sequence protein and mt-PA6 expressed similar low immunogenicity in the monkeys. The authors concluded that mt-PA6 would be very unlikely to present a serious immunogenic risk in humans, as the native sequence gives an antibody response in only a small number of patients who receive a single administration. In a more recent experiment in which chimpanzees were treated with t$\mathrm{PA}$, the authors also suggest that apes have predictive value in terms of neo-epitope detection (23). They show that modifications of the native PA do not lead to neo-epitopes and increased antibody response in chimpanzees, and therefore claim that these modified proteins are unlikely to give an antibody response in patients. Besides neo-epitope 
detection for tPA, non-human primates have also been used to study (neo-) epitopes in insulin. Rhesus monkeys were immunized with three forms of insulin: native sequence human insulin, LysPro insulin and porcine insulin. Of all 12 monkeys included in the experiment, one showed low levels of pretreatment anti-insulin antibodies and later on developed higher, but still low, levels of anti-insulin antibodies (14). These results show that alterations to amino-acid sequence of human insulin (LysPro insulin) do not induce neo-epitopes in rhesus monkeys. Similar is found in patients: native sequence insulin and LysPro insulin do not differ in immunogenicity (30).

Besides having potential predictive value in relative immunogenicity assessment and neo-epitope determination, non-human primates might also predict clinical effect of antibody formation, i.e. neutralizing auto-antibodies. In the report of the FDA meeting of the biological response modifiers advisory committee in 1999 (16), it is shown that non-human primates predicted an autoimmune reaction to thrombopoietin that was also observed clinically.

An example in which non-human primates are not suitable to predict (incidence of) immunogenicity in patients is interleukin 3. Gunn and colleagues used rhesus monkeys to assess immunogenicity of recombinant human interleukin-3 (31). All monkeys formed neutralizing antibodies against recombinant human interleukin 3, while $\sim 5 \%$ of patients form antibodies. Interestingly, homology between the interleukin 3 primary sequence of humans and rhesus monkeys is 93\% (alignment via BLAST).

It appears that similarity in amino-acid sequence does not guarantee that the animal model will display similar immunogenicity compared to patients. Other factors such as experimental setup, assays, disease state, or other (immune-related) genes could all contribute to a different immunogenicity profile (32).

In summary, non-human primates have predictive value for some therapeutic proteins; they may be useful to assess relative immunogenicity, neo-epitopes and development of neutralizing (cross reactive) antibodies.

Overall, animal models appear to have predictive potential when assessing relative immunogenicity, neoepitopes or breaking of tolerance. The studies described show that the predictive value is, in addition to the model and research question, also dependent on the protein. Only a few of the results from animal models have been clinically validated (or not), which makes it hard to draw conclusions on their actual predictive value.

\section{WHY ARE ANIMAL MODELS LIMITED?}

Transgenic mice expressing the protein of interest are often advocated as the preferred in vivo model to predict immunogenicity of therapeutic proteins. These models have the advantage of being immune tolerant, and mouse experiments encounter less ethical constraints compared to experiments using non-human primates. However, as shown in the previous section, these transgenic mice still have their limitations.

One of the reasons why animal models are limited in immunogenicity prediction is because the mechanisms underlying immunogenicity are still unknown and there may be important differences between the human and animal response. For example, if a therapeutic protein elicits a T-cell-dependent immune response (10), differences in T-cell subsets or MHC molecules between species might contribute to different immunogenicity. Also, if a therapeutic protein induces an immune response in a T-cellindependent manner (10), differences in B-cell subsets or dendritic cells could introduce species-dependent immunogenicity. In many cases, also patients have an altered immune system due to their disease or therapy.

Another reason for species-related immunogenicity could be a lack of genetic diversity of the animals. The animals used for immunogenicity testing are often inbred and therefore have almost identical genetic make-up, which contrasts the genetic diversity between humans. As genetic makeup has been implied in immunogenicity $(32,33)$, constriction in genetic variability of the animals can limit immunogenicity prediction for human populations. Even more, mice can have a genetic background that renders them insensitive to form an antibody response against certain therapeutic proteins (12).

Besides the animal model itself, the experimental setup will also affect predictive value. Differences in dose, immunization route, frequency of administration and impurities in the formulation have the potential to affect immunogenicity and its assessment (32). Moreover, with respect to product quality, preclinical protein products which are used in animal studies do not always reflect the final products used to treat patients. Another difficulty in translating animal results to human patients is a difference between labs in antibody assays that are used. These differences hamper comparison of results gained in different labs and therefore compromise predictive value of animal models. In patient research, several initiatives have begun to standardize antibody assays and thus improve comparability (34). Adjusting the antibody assays used in animal research to these standardized assays would likely improve predictive value of the models.

\section{ANIMAL MODELS TO STUDY THE MECHANISMS UNDERLYING IMMUNOGENICITY OF THERAPEUTIC PROTEINS}

Knowing why and how therapeutic proteins induce an antibody response will be key for the development of 
predictive tools which facilitate the development of therapeutic proteins with low immunogenicity. They may help to avoid a particular type of aggregate, design the optimal formulation, delete a certain epitope, and tailor glycosylation and other modifications. Transgenic animal models are an important tool in studying the immune mechanisms underlying immunogenicity of therapeutic proteins.

A major finding in these models is aggregates as a risk factor for immunogenicity. All protein formulations contain at least low levels of aggregates (35), but it is not known which type of aggregates at what level pose a risk. The first study looking into the possible impact of aggregates on immunogenicity using transgenic mice was performed by Braun and colleagues. They found that interferon alpha aggregates were able to induce an antibody response in transgenic immune-tolerant mice, while the monomer was not (36). Hermeling et al. $(18,37)$ continued on this data and studied which types of interferon alpha aggregates would be most immunogenic. Interestingly, aggregates with native-like structure appeared to have the highest immunogenicity. These oxidation-induced aggregates showed a dose-dependent antibody response (37), whereas oxidation alone did not, showing that the presence of aggregates, and not oxidation per sé, was crucial for immunogenicity (18). Also for recombinant human interferon beta such transgenic animal studies have been performed (22). A formulation with noncovalent aggregates induced a higher antibody response than a reformulated product with substantially less aggregates. A formulation with aggregates lacking native epitopes was poorly immunogenic. Rifkin and colleagues also showed that lowering aggregate content in interferon beta lowers immunogenicity in mice (38). The high immunogenicity of aggregated interferon beta-containing products in the transgenic mice corresponds to what is observed in patients with multiple sclerosis. Patients treated with therapeutic interferon beta with highest aggregate content (Betaferon) have the highest antibody responses (27). The data on immunogenicity of aggregates gives some insight into the molecular mechanisms underlying immunogenicity of therapeutic proteins, in particular interferon alpha and beta. Aggregates contain repetitive epitopes that might mimic viruses or bacteria. By binding and cross linking the B-cell receptors, such structures can induce antibody formation in a T-independent manner (10).

Animal models have given some insight into T-cell involvement. A recent study using the human interferon beta transgenic mice showed that no immunological memory was formed against aggregated human interferon beta, despite a clear antibody response against the protein (22). This correlates with clinical observations in which the antibody response against therapeutic interferon beta does not appear to induce immunological memory (39). Absence of immunological memory supports a lack of T-helper cell involvement, and possibly indicates a T-cell-independent mechanism involved in the antibody response. However, a study by Sauerborn et al. (unpublished data) in which all CD4 positive T-cells were depleted shows that T-cells are necessary for antibody formation. This corresponds to the finding that in animals (and humans) antibody isotype switching does take place, i.e. IgG subclasses are present in plasma. Isotype switching is usually a result of T-helper cell involvement and therefore contradicts a T-cell-independent immune response, although isotype switching has been described in absence of T-helper cell function (40).

The data so far in transgenic immune-tolerant mice are still ambiguous, and the immune mechanisms underlying immunogenicity of therapeutic proteins are neither a classical immune response against a foreign protein nor a clear T-cell-independent activation of B-cells (10). Future studies on T-cell subsets and cytokine profiles should shed more light on the cells involved in the antibody response.

A tantalizing idea would be to gain enough knowledge on the mechanisms underlying immunogenicity of therapeutic proteins to be able to induce, or maintain, tolerance against therapeutic proteins.

\section{CONCLUSION}

Animal models can be valuable in predicting immunogenicity of therapeutic proteins. However, the predictive value depends on the model and the research question. Additional treatment- and disease-related factors could additionally influence predictive value. Although more and more studies using animal models as predictors are published, the predictive value of animal models still needs to be fully established. In addition, animal models have proven valuable in elucidating the immune mechanism underlying immunogenicity and will certainly substantiate their value during future experiments.

Open Access This article is distributed under the terms of the Creative Commons Attribution Noncommercial License which permits any noncommercial use, distribution, and reproduction in any medium, provided the original author(s) and source are credited.

\section{REFERENCES}

1. Clarke JB. Mechanisms of adverse drug reactions to biologics. Handbook Exp Pharmacol. 2010: 453-74

2. Schellekens H. The immunogenicity of therapeutic proteins. Discov Med. 2010;9:560-4. 
3. de Vries MK, Brouwer E, van der Horst-Bruinsma IE, Spoorenberg A, van Denderen JC, Jamnitski A, et al. Decreased clinical response to adalimumab in ankylosing spondylitis is associated with antibody formation. Ann Rheum Dis. 2009;68:1787-8.

4. Schellekens H. Immunogenicity of therapeutic proteins: clinical implications and future prospects. Clin Ther. 2002;24:1720-40.

5. Schellekens H. Immunologic mechanisms of EPO-associated pure red cell aplasia. Best Pract Res Clin Haematol. 2005;18:473-80.

6. Wolbink GJ, Aarden LA, Dijkmans BA. Dealing with immunogenicity of biologicals: assessment and clinical relevance. Curr Opin Rheumatol. 2009;21:211-5.

7. Bender NK, Heilig CE, Droll B, Wohlgemuth J, Armbruster FP, Heilig B. Immunogenicity, efficacy and adverse events of adalimumab in RA patients. Rheumatol Int. 2007;27:269-74.

8. Vultaggio A, Matucci A, Nencini F, Pratesi S, Parronchi P, Rossi $\mathrm{O}$, et al. Anti-infliximab $\mathrm{IgE}$ and non-IgE antibodies and induction of infusion-related severe anaphylactic reactions. Allergy. 2010;65:657-61.

9. EMA. Guideline on immunogenicity assessment of biotechnologyderived therapeutic proteins. 2007. Ref Type: Conference Proceeding

10. Sauerborn M, Brinks V, Jiskoot W, Schellekens H. Immunological mechanism underlying the immune response to recombinant human protein therapeutics. Trends Pharmacol Sci. 2010;31:53-9.

11. Jones AJ. The use of an animal immunogenicity model in the development of protropin somatrem (methionyl human growth hormone). Dev Biol (Basel). 2002;109:107-18.

12. Ottesen JL, Nilsson P, Jami J, Weilguny D, Duhrkop M, Bucchini $\mathrm{D}$, et al. The potential immunogenicity of human insulin and insulin analogues evaluated in a transgenic mouse model. Diabetologia. 1994;37:1178-85.

13. van Beers MM, Sauerborn M, Gilli F, Hermeling S, Brinks V, Schellekens $\mathrm{H}$, et al. Hybrid transgenic immune tolerant mouse model for assessing the breaking of $\mathrm{B}$ cell tolerance by human interferon beta. J Immunol Methods. 2010;352:32-7.

14. Zwickl CM, Smith HW, Zimmermann JL, Wierda D. Immunogenicity of biosynthetic human LysPro insulin compared to nativesequence human and purified porcine insulins in rhesus monkeys immunized over a 6 -week period. Arzneimittelforschung. 1995;45:524-8.

15. Zwickl CM, Hughes BL, Piroozi KS, Smith HW, Wierda D. Immunogenicity of tissue plasminogen activators in rhesus monkeys: antibody formation and effects on blood level and enzymatic activity. Fundam Appl Toxicol. 1996;30:243-54.

16. Center for Biologics Evaluation and Research. Meeting of the biological response modifiers advisory committee. July 15, Bethesda MD. Food and Drug Administration. 1999. Ref Type: Conference Proceeding

17. Zwickl CM, Cocke KS, Tamura RN, Holzhausen LM, Brophy GT, Bick PH, et al. Comparison of the immunogenicity of recombinant and pituitary human growth hormone in rhesus monkeys. Fundam Appl Toxicol. 1991;16:275-87.

18. Hermeling S, Aranha L, Damen JM, Slijper M, Schellekens H, Crommelin DJ, et al. Structural characterization and immunogenicity in wild-type and immune tolerant mice of degraded recombinant human interferon alpha2b. Pharm Res. 2005;22:1997-2006.

19. Koren E, Zuckerman LA, Mire-Sluis AR. Immune responses to therapeutic proteins in humans-clinical significance, assessment and prediction. Curr Pharm Biotechnol. 2002;3:349-60.

20. Jaber A, Driebergen R, Giovannoni G, Schellekens H, Simsarian J, Antonelli M. The Rebif new formulation story: it's not trials and error. Drugs R D. 2007;8:335-48.

21. Bellomi F, Muto A, Palmieri G, Focaccetti C, Dianzani C, Mattei $\mathrm{M}$, et al. Immunogenicity comparison of interferon beta-la preparations using the $\mathrm{BALB} / \mathrm{c}$ mouse model: assessment of a new formulation for use in multiple sclerosis. New Microbiol. 2007;30:241-6.

22. van Beers MM, Sauerborn M, Gilli F, Brinks V, Schellekens H, Jiskoot W. Aggregated recombinant human interferon beta induces antibodies but no memory in immune-tolerant transgenic mice. Pharm Res. 2010

23. Katsutani N, Yoshitake S, Takeuchi H, Kelliher JC, Couch RC, Shionoya H. Immunogenic properties of structurally modified human tissue plasminogen activators in chimpanzees and mice. Fundam Appl Toxicol. 1992;19:555-62.

24. Stewart TA, Hollingshead PG, Pitts SL, Chang R, Martin LE, Oakley H. Transgenic mice as a model to test the immunogenicity of proteins altered by site-specific mutagenesis. Mol Biol Med. 1989;6:275-81.

25. Whiteley PJ, Lake JP, Selden RF, Kapp JA. Tolerance induced by physiological levels of secreted proteins in transgenic mice expressing human insulin. J Clin Invest. 1989;84:1550-4.

26. Hermeling S, Jiskoot W, Crommelin D, Bornaes C, Schellekens H. Development of a transgenic mouse model immune tolerant for human interferon beta. Pharm Res. 2005;22:847-51.

27. Bertolotto A, Deisenhammer F, Gallo P, Solberg SP. Immunogenicity of interferon beta: differences among products. J Neurol. 2004;251 Suppl 2:II15-24.

28. Lee HJ, Riley G, Johnson O, Cleland JL, Kim N, Charnis M, et al. In vivo characterization of sustained-release formulations of human growth hormone. J Pharmacol Exp Ther. 1997;281:1431-9.

29. Fradkin AH, Carpenter JF, Randolph TW. Immunogenicity of aggregates of recombinant human growth hormone in mouse models. J Pharm Sci. 2009;98:3247-64.

30. Fineberg NS, Fineberg SE, Anderson JH, Birkett MA, Gibson RG, Hufferd S. Immunologic effects of insulin lispro [Lys (B28), Pro (B29) human insulin] in IDDM and NIDDM patients previously treated with insulin. Diabetes. 1996;45:1750-4.

31. Gunn H. Immunogenicity of recombinant human interleukin-3. Clin Immunol Immunopathol. 1997;83:5-7.

32. Schellekens H. Factors influencing the immunogenicity of therapeutic proteins. Nephrol Dial Transplant. 2005;20 Suppl 6:vi3-9.

33. De Groot AS, Scott DW. Immunogenicity of protein therapeutics. Trends Immunol. 2007;28:482-90.

34. Schellekens H. The immunogenicity of therapeutic proteins and the Fabry antibody standardization initiative. Clin Ther. 2008;30 (Suppl B):S50-1.

35. Weiss WF, Young TM, Roberts CJ. Principles, approaches, and challenges for predicting protein aggregation rates and shelf life. J Pharm Sci. 2009;98:1246-77.

36. Braun A, Kwee L, Labow MA, Alsenz J. Protein aggregates seem to play a key role among the parameters influencing the antigenicity of interferon alpha (IFN-alpha) in normal and transgenic mice. Pharm Res. 1997;14:1472-8.

37. Hermeling S, Schellekens H, Maas C, Gebbink MF, Crommelin DJ, Jiskoot W. Antibody response to aggregated human interferon alpha2b in wild-type and transgenic immune tolerant mice depends on type and level of aggregation. J Pharm Sci. 2006;95:1084-96.

38. Rifkin RA, Maggio ET, Dike S, Kerr DA, Levy M. n-Dodecyl-betaD: -maltoside inhibits aggregation of human interferon-beta- $1 \mathrm{~b}$ and reduces its immunogenicity. J Neuroimmune Pharmacol. 2010

39. Perini P, Facchinetti A, Bulian P, Massaro AR, Pascalis DD, Bertolotto $\mathrm{A}$, et al. Interferon-beta (INF-beta) antibodies in interferon-betala- and interferon-betalb-treated multiple sclerosis patients. Prevalence, kinetics, cross-reactivity, and factors enhancing interferon-beta immunogenicity in vivo. Eur Cytokine Netw. 2001;12:56-61.

40. Gao N, Jennings P, Yuan D. Requirements for the natural killer cell-mediated induction of $\mathrm{IgGl}$ and IgG2a expression in $\mathrm{B}$ lymphocytes. Int Immunol. 2008;20:645-57. 